\title{
Electrochemical Behavior of Titanium and Its Alloys as Dental Implants in Normal Saline
}

\author{
Rahul Bhola, Shaily M. Bhola, Brajendra Mishra, and David L. Olson \\ Department of Metallurgical and Materials Engineering, Colorado School of Mines, Golden, CO 80401, USA \\ Correspondence should be addressed to Rahul Bhola, rbhola@mines.edu
}

Received 21 January 2009; Accepted 19 February 2009

Recommended by Claudio Fontanesi

\begin{abstract}
The electrochemical behavior of pure titanium and titanium alloys in a simulated body fluid (normal saline solution) has been tested, and the results have been reported. The significance of the results for dental use has been discussed. The tests also serve as a screening test for the best alloy system for more comprehensive long-term investigations.
\end{abstract}

Copyright (C) 2009 Rahul Bhola et al. This is an open access article distributed under the Creative Commons Attribution License, which permits unrestricted use, distribution, and reproduction in any medium, provided the original work is properly cited.

\section{Introduction}

Commercially pure titanium and titanium alloys are known for their use in dental practice owing to their good corrosion resistance, biocompatibility, and biofunctionality in the human body [1].

Titanium is a thermodynamically reactive metal as suggested by its relatively negative reversible potential in the electrochemical series [2]. It gets readily oxidized during exposure to air and electrolytes to form oxides, hydrated complexes, and aqueous cationic species. The oxides and hydrated complexes act as barrier layers between the titanium surface and the surrounding environment and suppress the subsequent oxidation of titanium across the metal/barrier layer/solution interface. Even if the barrier layer gets disrupted, it can get reformed very easily, leading to spontaneous repassivation. A review of literature reveals that extensive work has been done on the use of titanium alloys as prostheses when the alloy comes in contact with saliva [35]. Whereas when titanium alloys are used as implants, the alloy remains in contact with saliva only during the transition period of healing of the bony socket and gingiva (gum) but when it is capped with the crown, it is in contact with only bone cells for the rest of its life. The aim of this study is to keep in focus the use of titanium alloy as an implant inside the bone tissue and hence normal saline solution was used to simulate the extracellular interstitial environment. The decrease in $\mathrm{pH}$ can occur inside the bone tissue owing to surgical trauma, infection $[6,7]$ as well as the healing process of the bony socket. $\mathrm{Ti}^{3+}$ ions, if produced, can hydrolyze to further acidify the area [8]. Acidification can also be observed if crevice corrosion occurs in the clefts between the implant and the crown [5]. According to Black [9], the potential of a metallic biomaterial can range from -1 to $1.2 \mathrm{~V}$ versus SCE in the human body. It is, thus, significant to study the electrochemical behavior of titanium in this potential range.

Electrochemical corrosion behavior of commercially pure titanium (grades Ti1 \& Ti2) and its alloys, Ti64, TiOs, Ti15Mo, and TMZF in normal saline solution was analyzed at the body temperature of $37^{\circ} \mathrm{C}$.

\section{Experimental}

2.1. Materials Preparation. Titanium alloy grades Ti1, Ti2, Ti64, TiOs, Ti15Mo, and TMZF of compositions Til $(0.1 \% \mathrm{C}, 0.2 \% \mathrm{Fe}, 0.015 \% \mathrm{H}, 0.03 \% \mathrm{~N}, 0.18 \% \mathrm{O}$, and $99.47 \% \mathrm{Ti}), \quad \mathrm{Ti} 2 \quad(0.1 \% \mathrm{C}, \quad 0.3 \% \mathrm{Fe}, \quad 0.015 \% \mathrm{H}, \quad 0.03 \% \mathrm{~N}$, $0.25 \% \mathrm{O}$, and $99.30 \% \mathrm{Ti})$, Ti64 $(0.1 \% \mathrm{C}, 0.2 \% \mathrm{Fe}, 0.015 \% \mathrm{H}$, $0.03 \% \mathrm{~N}, \quad 0.2 \% \mathrm{O}, \quad 6 \% \mathrm{Al}, \quad 4 \% \mathrm{~V}$, and $89.45 \% \mathrm{Ti})$, TiOs (0.05\% $, 0.05 \% \mathrm{Fe}, 0.015 \% \mathrm{H}, 0.02 \% \mathrm{~N}, 0.15 \% \mathrm{O}, 35.5 \% \mathrm{Nb}$, $5.7 \% \mathrm{Ta}, 7.3 \% \mathrm{Zr}$, and $51.21 \% \mathrm{Ti})$, Ti15Mo $(0.05 \% \mathrm{C}, 0.1 \% \mathrm{Fe}$, $0.015 \% \mathrm{H}, \quad 0.01 \% \mathrm{~N}, 0.15 \% \mathrm{O}, 15 \% \mathrm{Mo}$, and $84.67 \% \mathrm{Ti})$, and TMZF $(0.02 \% \mathrm{C}, 2 \% \mathrm{Fe}, 0.02 \% \mathrm{H}, 0.01 \% \mathrm{~N}, 0.18 \% \mathrm{O}$, $6 \% \mathrm{Zr}, 12 \% \mathrm{Mo}$, and $79.77 \% \mathrm{Ti})$ were used for the present investigation. Available cuboidal and cylindrical rods were cut to expose cross-section areas of $0.855 \mathrm{~cm}^{2}$ for Ti1, $1.0 \mathrm{~cm}^{2}$ for Ti2, $1.5525 \mathrm{~cm}^{2}$ for Ti64, $1.3270 \mathrm{~cm}^{2}$ for TiOs, $0.4869 \mathrm{~cm}^{2}$ for Ti15Mo, and $2.7606 \mathrm{~cm}^{2}$ for TMZF 


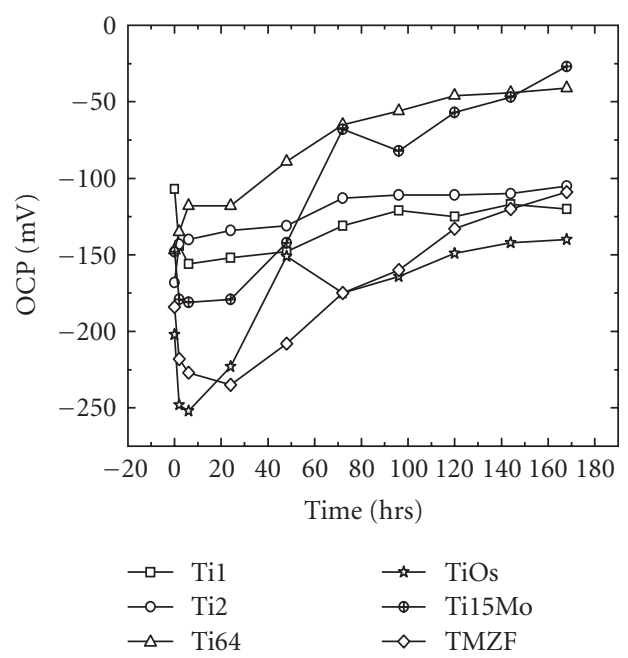

Figure 1: Open circuit potential values of alloys as a function of time at $37^{\circ} \mathrm{C}$.

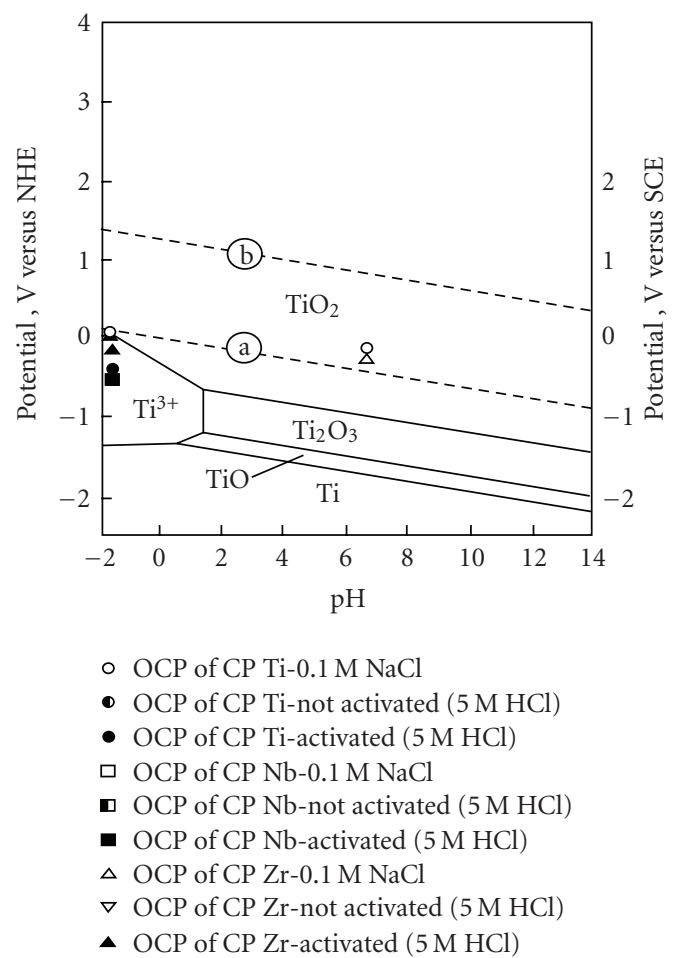

Figure 2: Pourbaix diagram for titanium at $37^{\circ} \mathrm{C}$.

as working electrodes. Normal saline solution $\left(5.26 \mathrm{gL}^{-1}\right.$ sodium chloride, $2.22 \mathrm{gL}^{-1}$ anhy. sodium acetate, $5.02 \mathrm{gL}^{-1}$ sodium gluconate, $0.37 \mathrm{gL}^{-1}$ potassium chloride, and $0.3 \mathrm{gL}^{-1}$ magnesium chloride hexahydrate) having $\mathrm{pH} 6.6$ was used to carry out the electrochemical testing of alloys.

2.2. Measurements. A Princeton Applied Research Potentiostat $273 \mathrm{~A}$ was used for the electrochemical measurements. A three-electrode cell assembly consisting of titanium alloy as the working electrode, platinum wire as the counter electrode, and a saturated calomel electrode as the reference

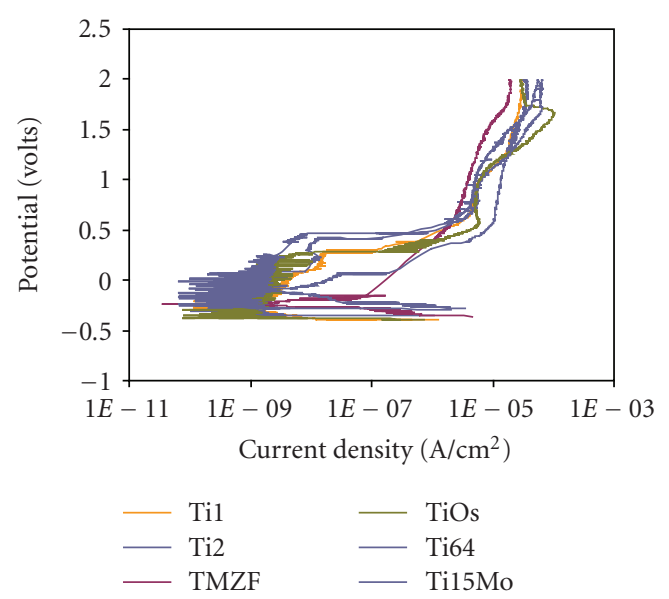

Figure 3: Potentiodynamic curves for the alloys at $37^{\circ} \mathrm{C}$.

electrode was used. $450 \mathrm{~mL}$ of normal saline solution was used for the immersion and electrochemical testing of the alloys.

Open Circuit Potential (OCP). Open circuit potential values of the alloys were measured just after immersion, followed by a duration of 2, 6, and 24 hours up to seven days.

Tafel. After the end of the seven days, Tafel curves of various alloys were obtained by polarizing each electrode from $-250 \mathrm{mV}$ versus OCP to $2 \mathrm{~V}$ with an ASTM scan rate of $1 \mathrm{mV} / \mathrm{s}[10]$.

Cyclic Polarization. Cyclic polarization measurements were extended after Tafel measurements by choosing a vertex potential of $2 \mathrm{~V}$, at which the scan was reversed, and the final potential was $-250 \mathrm{mV}$ versus OCP.

\section{Results and Discussion}

It can be seen from Figure 1 and Table 1 that the OCP values for all alloys have shown an overall increase for the time duration of seven days, despite showing a small decrease in a few intervals.

The OCP shift in the noble direction for the alloys suggests the formation of a passive film that acts as a barrier for metal dissolution and reduces the corrosion rate. The shift can also suggest that the composition of corrosive medium might be changing in the implant cavity but since large volume of solution is used in testing, that can be neglected. The potential increase shows that the alloys become thermodynamically more stable with time. According to Blackwood et al. [11], the shift in OCP to positive values lowers the corrosion rate by reducing the driving force of the cathodic reaction and increasing the thickness of the passive oxide film. The initial decrease observed in the OCP values for Til, TiOs, and TMZF suggests the initial dissolution of the air-formed oxide film till the formation of a new oxide in solution [12]. 


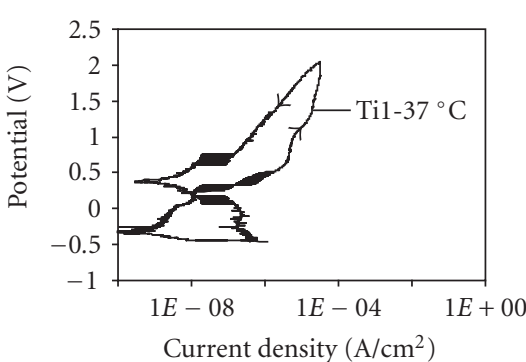

(a) Ti1

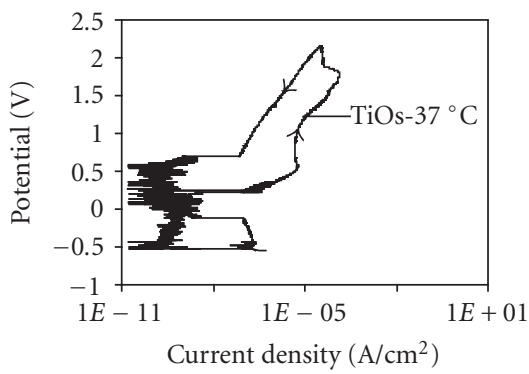

(d) $\mathrm{TiOs}$

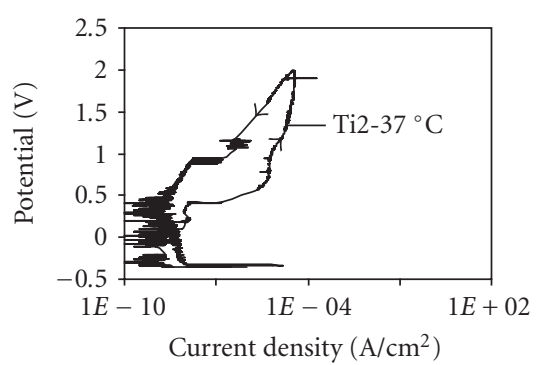

(b) Ti2

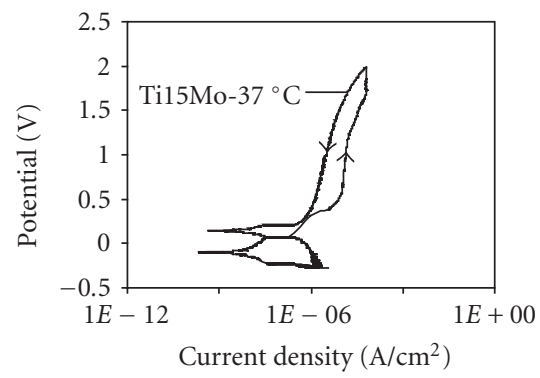

(e) Ti15Mo

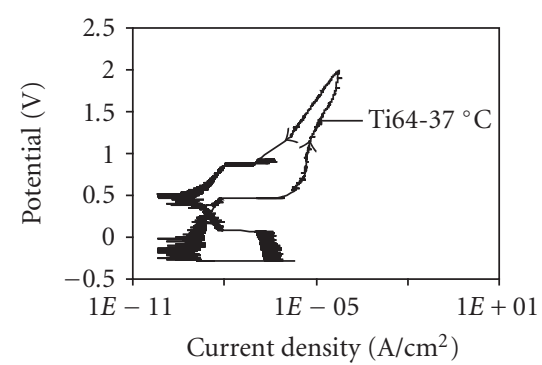

(c) Ti64

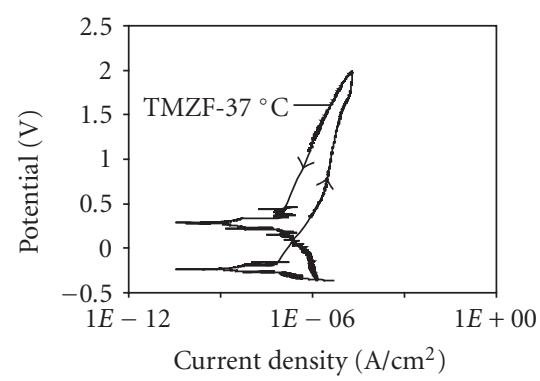

(f) TMZF

Figure 4: Cyclic polarization curves for alloys (a)-(f) at $37^{\circ} \mathrm{C}$.

TABLE 1: Open circuit potential values of alloys with change in time at $37^{\circ} \mathrm{C}$.

\begin{tabular}{lcccccccccc}
\hline \multirow{2}{*}{ Material } & \multicolumn{1}{c}{ Open circuit potential $(\mathrm{mV})$} \\
& On immersion & 2 hrs. & 6 hrs. & 1 day & 2 days & 3 days & 4 days & 5 days & 6 days & 7 days \\
\hline Ti1 & -107 & -144 & -156 & -152 & -148 & -131 & -121 & -125 & -117 & -120 \\
Ti2 & -168 & -143 & -140 & -134 & -131 & -113 & -111 & -111 & -110 & -105 \\
Ti64 & -147 & -135 & -118 & -118 & -89 & -65 & -56 & -46 & -44 & -41 \\
TiOs & -202 & -248 & -252 & -223 & -151 & -175 & -164 & -149 & -142 & -140 \\
Ti15Mo & -148 & -179 & -181 & -179 & -142 & -68 & -82 & -57 & -47 & -27 \\
TMZF & -184 & -218 & -227 & -235 & -208 & -175 & -160 & -133 & -120 & -109 \\
\hline
\end{tabular}

The $\mathrm{pH}$ values of all alloys in normal saline solution of pH 6.6 were less than 8 till seven days of immersion. Figure 2 shows the $\mathrm{pH}$-potential Pourbaix diagram for titaniumwater system at $37^{\circ} \mathrm{C}[13]$, with potential also shown with respect to SCE on another $y$-axis. The corresponding region of $\mathrm{pH}(6.6-8)$ and potential to which the present system is studied is similar to that of $\mathrm{TiO}_{2}$ in the Pourbaix diagram indicating the fact that under steady-state conditions, the alloys form a stable oxide layer of $\mathrm{TiO}_{2}$.

Figure 3 shows the potentiodynamic curves for the alloys at $37^{\circ} \mathrm{C}$. The corresponding corrosion parameters are given in Table 2, and passivation parameters are given in Table 3. [14]

The corrosion rate was calculated using the expression

$$
\text { Corrosion rate }\left(\frac{\mathrm{mm}}{\text { year }}\right)=\frac{0.00327 \times \mathrm{E} . \mathrm{W} . \times I_{\text {corr }}}{\rho},
$$

where E.W. = equivalent weight, $I_{\text {corr }}=$ current density in $\mu \mathrm{A} / \mathrm{cm}^{2}$, and $\rho=$ density in $\mathrm{g} / \mathrm{cm}^{3}$.

The corrosion rates observed are in the order Ti15Mo $>$ Ti2 $>$ TMZF $>$ Ti1 $>$ Ti64 > TiOs. The corrosion rates observed are very low and belong to the outstanding corrosion resistance category of less than $0.02 \mathrm{~mm} /$ year as classified by Fontana [15]. Studies have further revealed that to prevent tissue damage and irritation, the corrosion rate of a metallic implant should be less than $2.5 \times 10^{-4} \mathrm{~mm} /$ year [16]. The difference between the passivation potential and $E_{\text {corr }}$ can provide an indication of the ease of passivation of the alloys. The lower the difference is, the easier the passivation will be. The difference follows the order TMZF $>$ Ti15Mo $>$ Til $>$ Ti2 $>$ TiOs $>$ Ti64 .

Cyclic polarization method is a highly useful method for determining the susceptibility of a metal or alloy to pitting [17]. From Figures 4(a)-4(f), it can be seen that at the vertex potential of $2 \mathrm{~V}$ when the scan reverses its direction, the reverse scan starts left of the forward scan curve, that is, towards the low current density region. This type of the cyclic polarization curve is known to resist localized corrosion [18]. It is also observed that the reverse scan curves meet the forward scan curve along the passive range. The reverse scan curves show lower current densities as can be seen in Table 2 except for Ti1 and Ti2. The potentials for the reverse scan 
TABLE 2: Corrosion parameters for the forward and reverse scans for the alloys at $37^{\circ} \mathrm{C}$ after seven days.

\begin{tabular}{lccccc}
\hline Material & & Forward scan & \multicolumn{2}{c}{ Reverse scan } \\
& $E_{\text {corr }}(\mathrm{mV})$ & $I_{\text {corr }}\left(\mathrm{nA} / \mathrm{cm}^{2}\right)$ & Corr. rate $* 10^{13}(\mathrm{~mm} / \mathrm{y})$ & $E_{\text {corr }}(\mathrm{mV})$ & 369.6 \\
$I_{\text {corr }}\left(\mathrm{nA} / \mathrm{cm}^{2}\right)$ \\
\hline Ti1 & -298.2 & 0.934 & 3.43 & 338 & 2.27 \\
Ti2 & -69 & 1.6 & 5.88 & 427.3 & 0.5 \\
Ti64 & -220 & 0.708 & 2.65 & 322.1 & 0.00531 \\
TiOs & -193.3 & 0.222 & 0.64 & 133.7 & 3.19 \\
Ti15Mo & -139.9 & 4.68 & 15.67 & 225.9 & 0.658 \\
TMZF & -256.7 & 1.26 & 4.19 & 2 & \\
\hline
\end{tabular}

TABLe 3: Passivation parameters for the alloys at $37^{\circ} \mathrm{C}$ after seven days.

\begin{tabular}{lcccl}
\hline Material & $E_{\text {pass }}(\mathrm{mV})$ & $I_{\text {pass }}\left(\mu \mathrm{A} / \mathrm{cm}^{2}\right)$ & $E_{\text {corr }}(\mathrm{mV})$ & $\begin{array}{l}E_{\text {pass }}- \\
E_{\text {corr }}(\mathrm{mV})\end{array}$ \\
\hline Ti1 & 146 & 0.013 & -298.2 & 442.2 \\
Ti2 & 359 & 0.006 & -69 & 428 \\
Ti64 & -104 & 0.00173 & -220 & 116 \\
TiOs & -72 & 0.00143 & -193.3 & 121.3 \\
Ti15Mo & 569 & 10.02 & -139.9 & 708.9 \\
TMZF & 644 & 2.37 & -256.7 & 900.7 \\
\hline
\end{tabular}

curves are more positive than those for the forward scan. These results show that a stable oxide film is formed during the forward scan.

\section{Conclusions}

(1) In normal saline solution, all alloys exhibit a high corrosion resistance, and the corrosion rates observed fall in the acceptable range for biocompatibility of metallic implants.

(2) All alloys show considerable ennoblement and form a stable oxide film of $\mathrm{TiO}_{2}$ as indicated by their corresponding $\mathrm{pH}$ and potential position in the Pourbaix diagram.

(3) From the cyclic polarization curves obtained, it can be concluded that the alloys resist localized corrosion.

\section{References}

[1] J. Lemons, R. Venugopalan, and L. Lucas, "Corrosion and biodegradation," in Handbook of Biomaterials Evaluation, A. F. von Recum, Ed., pp. 155-167, Taylor \& Francis, New York, NY, USA, 1999.

[2] S. Yu, Corrosion Resistance of Titanium Alloys, Corrosion: Fundamentals, Testing and Protection, vol. 13A of ASM Handbook, ASM International, Materials Park, Ohio, USA, 2003.

[3] A. M. Al-Mayouf, A. A. Al-Swayih, N. A. Al-Mobarak, and A. S. Al-Jabab, "Corrosion behavior of new titanium alloy for dental implant applications," The Saudi Dental Journal, vol. 14, no. 3, pp. 118-125, 2002.

[4] M. Sharma, A. V. Ramesh Kumar, N. Singh, N. Adya, and B. Saluja, "Electrochemical corrosion behavior of dental/implant alloys in artificial saliva," Journal of Materials Engineering and Performance, vol. 17, no. 5, pp. 695-701, 2008.
[5] K. Elagli, M. Traisnel, and H. F. Hildebrand, "Electrochemical behaviour of titanium and dental alloys in artificial saliva," Electrochimica Acta, vol. 38, no. 13, pp. 1769-1774, 1993.

[6] M. L. Escudero, M. F. López, J. Ruiz, M. C. García-Alonso, and H. Canahua, "Comparative study of the corrosion behavior of MA-956 and conventional metallic biomaterials," Journal of Biomedical Materials Research Part A, vol. 31, no. 3, pp. 313317, 1996.

[7] T. Eliades, "Passive film growth on titanium alloys: physicochemical and biologic considerations," International Journal of Oral and Maxillofacial Implants, vol. 12, no. 5, pp. 621-627, 1997.

[8] D. G. Kolman and J. R. Scully, "On the repassivation behavior of high-purity titanium and selected $\alpha, \beta$, and $\beta+\alpha$ titanium alloys in aqueous chloride solutions," Journal of the Electrochemical Society, vol. 143, no. 6, pp. 1847-1860, 1996.

[9] J. Black, in Biological Performance of Materials: Fundamentals of Biocompatibility, pp. 38-60, Marcel Decker, New York, NY, USA, 1992.

[10] ASTM Standard F2129-06, ASTM International, USA.

[11] D. J. Blackwood, A. W. C. Chua, K. H. W. Seah, R. Thampuran, and S. H. Teoh, "Corrosion behaviour of porous titaniumgraphite composites designed for surgical implants," Corrosion Science, vol. 42, no. 3, pp. 481-503, 2000.

[12] U. R. Evans, The Corrosion of Metals, Edward Arnold, London, UK, 1960.

[13] S. Yu, Corrosion: Fundamentals, Testing, and Protection, vol. 13A of ASM Handbook, ASM International, Materials Park, Ohio, USA, 2003.

[14] D. A. Jones, Principles and Prevention of Corrosion, Prentice Hall, Upper Saddle River, NJ, USA, 2nd edition, 1995.

[15] M. G. Fontana, Corrosion Engineering, McGraw-Hill, New York, NY, USA, 3rd edition, 1986.

[16] W. D. Callister Jr., Materials Science and Engineering: An Introduction, John Wiley \& Sons, New York, NY, USA, 7th edition, 2007.

[17] P. R. Roberge, Handbook of Corrosion Engineering, McGraw Hill, New York, NY, USA, 2000.

[18] D. C. Silverman, "Tutorial on cyclic potentiodynamic polarization technique," in Proceedings of the CORROSION/98 Research Topical Symposia, NACE International, San Diego, Calif, USA, March 1998, paper no. 299. 


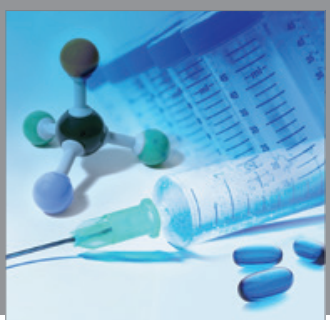

International Journal of

Medicinal Chemistry

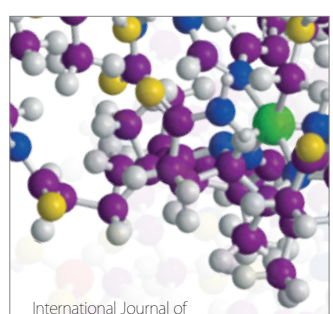

Carbohydrate Chemistry

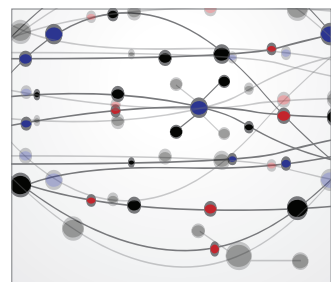

The Scientific World Journal
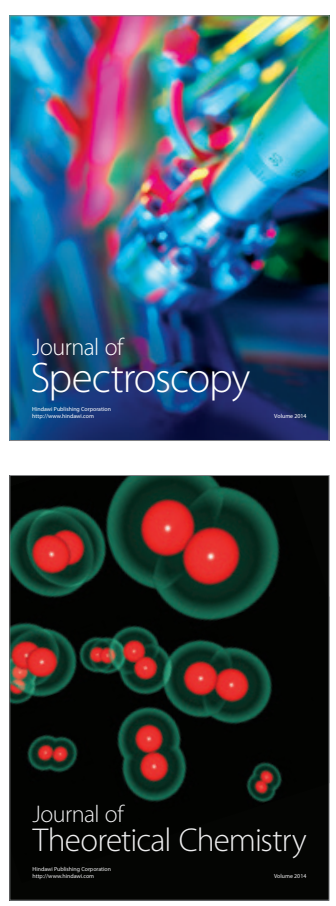
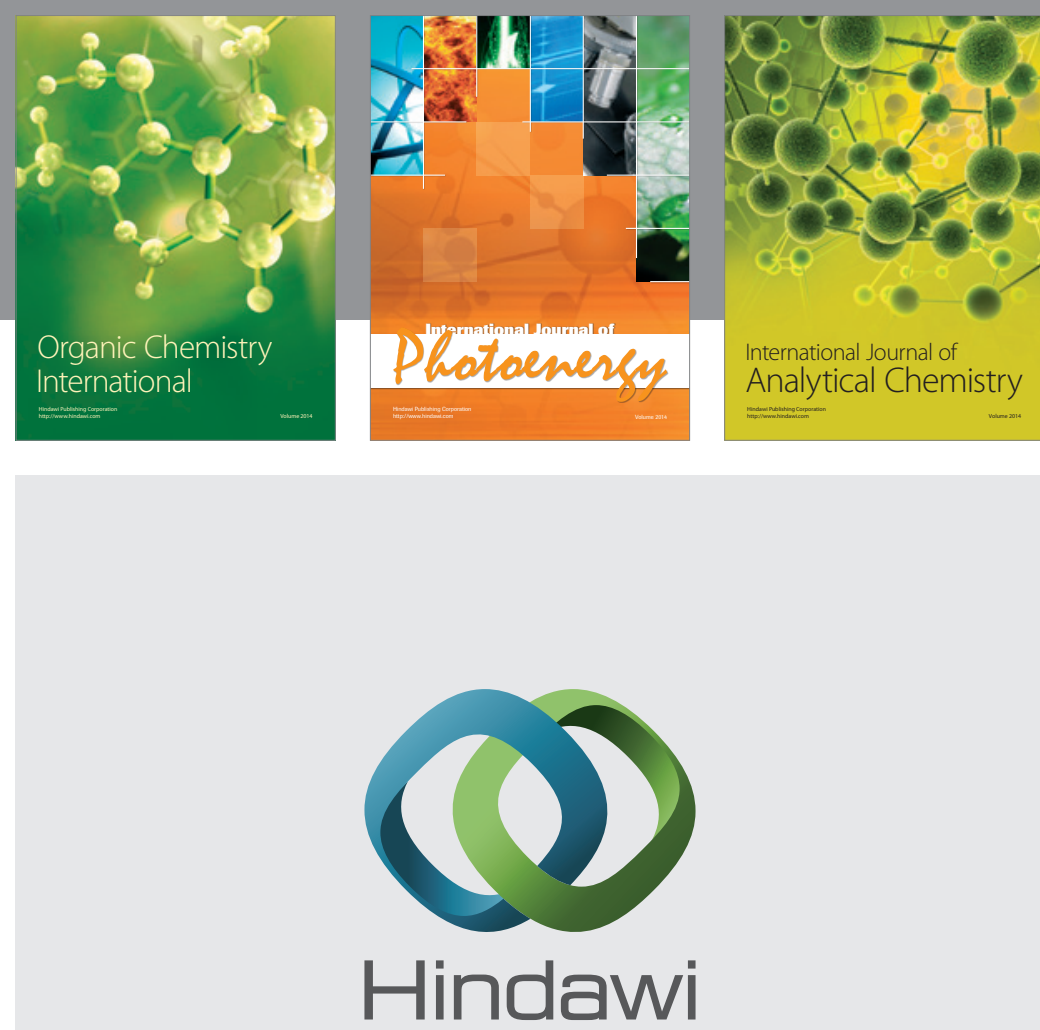

Submit your manuscripts at

http://www.hindawi.com
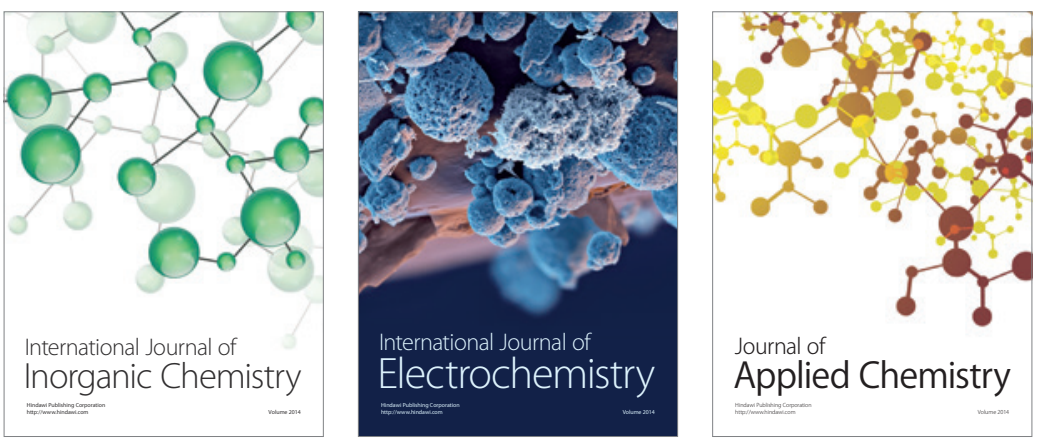

Journal of

Applied Chemistry
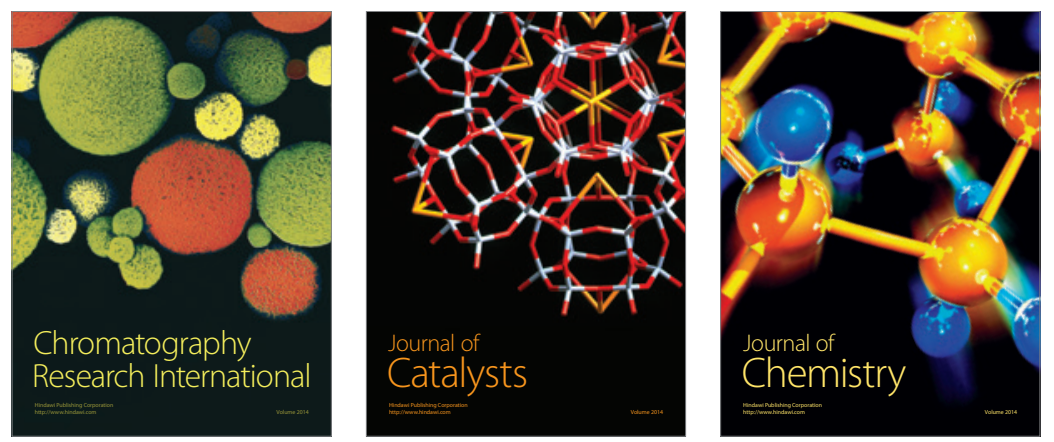
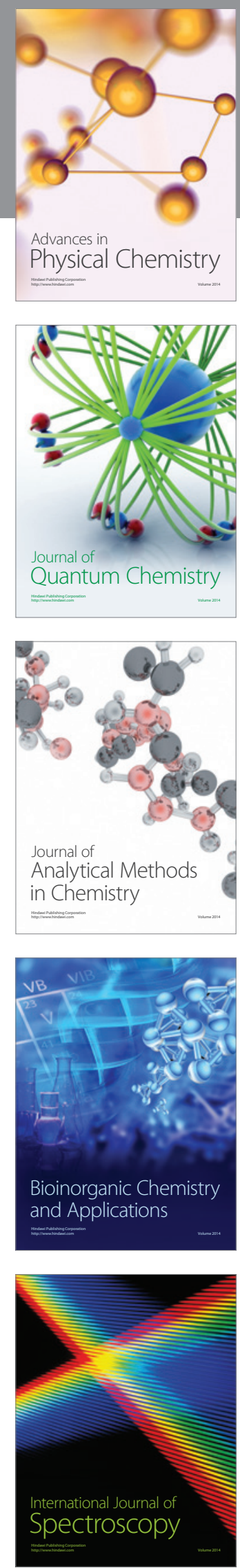